\title{
INDIAN POLICY OF JOHN ADAMS ADMINISTRATION: THE CONTOURS OF THE POLITICAL COURSE
}

\author{
Timur V. Nelin \\ Candidate of Sciences (History), \\ Acting Head of the Department of International Relations and Foreign Area Studies, \\ Director, Center of American Studies "Americana", \\ Volgograd State University \\ timur_nelin@mail.ru \\ Prosp. Universitetsky, 100, 400062 Volgograd, Russian Federation.
}

\begin{abstract}
The article considers the policy of John Adams administration toward the Native Americans in 1797-1801. This subject was not investigated by Russian scholars. Foreign scholars researched the Indian policy of the second president of the United States only in general terms. They paid attention to the views of John Adams towards the Natives and to the common principals of such policy. In fact the details of the policy have to be explored. The lack of attention by the scholars towards John Adams' Indian policy can be explained by the fact that the period of 1797-1801 was not rich in significant events in Indian-White relations. There were no great conflicts between the two nations. It seems that John Adams was not an enthusiastic reformer. However the problems of the frontier existed and they could be solved. The second president of the USA did his work and tried to reduce the negative influence of foreign agents on the Native Americans. In this task he had to use the experience of George Washington, who was the real enthusiast in implementing the Indian policy. The other issue that had to be solved dealt with the Indian lands. John Adams administration did the best to overcome all difficulties with minimal losses. The author tries to acquit John Adams and to show the reasons why his Indian policy was not so bright as George Washington's or Thomas Jefferson's ones.
\end{abstract}

Key words: U.S. history, John Adams, Native Americans, Indian policy, frontier.

\section{ИНДЕЙСКАЯ ПОЛИТИКА АДМИНИСТРАЦИИ ДЖОНА АДАМСА: КОНТУРЫ ПОЛИТИЧЕСКОГО КУРСА}

\section{Тимур Владимирович Нелин}

Кандидат исторических наук, исполняющий обязанности заведующего кафедрой международных отношений и зарубежного регионоведения, директор Центра американских исследований «Americana», Волгоградский государственный университет timur_nelin@mail.ru просп. Университетский, 100, 400062 г. Волгоград, Российская Федерация

Аннотация. В статье рассматривается политика, которую проводила администрация Джона Адамса в отношении коренных американцев в период с 1797 по 1801 год. В отечественной историографии эта тема не исследовалась. Зарубежные ученые ее касались лишь в самых общих чертах. Считается, что Дж. Адамс, второй президент США, не был энтузиастом в решении индейского вопроса. Однако это не означает, что в годы его президентства проблема взаимоотношений белых и индейцев не была актуальной. В статье показа- 
но, какие проблемы возникали перед администрацией США в этом вопросе и каким образом они решались. Автор делает попытку реабилитировать Дж. Адамса в глазах ученых, объясняя причины, по которым индейская политика второго президента США не была столь яркой, как у его коллег Джорджа Вашингтона и Томаса Джефферсона.

Ключевые слова: история США, Джон Адамс, коренные американцы, индейская политика, фронтир.

В конце XVIII - начале XIX в. Соединенные Штаты Америки проводили достаточно активную политику в отношении коренных американцев. Особенно заметными в решении индейского вопроса были первый и третий президенты США: Джордж Вашингтон и Томас Джефферсон. Их индейская политика относительно неплохо освещена в литературе [16, p. 61-144; 25]. Иначе дело обстоит с политикой второго президента страны - Джона Адамса. В отечественной историографии эта сторона его политической карьеры не рассматривалась. Зарубежные исследователи индейской политике администрации Дж. Адамса также особого внимания не уделяли. Как справедливо отмечает американский историк Дэниел Уснер, найти какую-либо информацию об отношении Дж. Адамса к индейцам и о его индейской политике сложно как в старых, так и в новых работах, посвященных второму президенту США. Те же авторы, которые исследуют федеральную политику Соединенных Штатов в отношении коренных американцев, по словам Д. Уснера, говорят об индейской политике Дж. Адамса лишь бегло и зачастую принижают роль второго президента в этом вопросе [24, p. 608]. В данном случае с Д. Уснером сложно не согласиться. Один из наиболее авторитетных исследователей политики США в отношении коренных американцев, Фрэнсис Пол Пруча, охарактеризовал индейскую политику Дж. Адамса буквально одной фразой: «Будучи президентом, Адамс, казалось, мало интересовался проблемой индейцев, хотя впоследствии гордился тем, что сохранил мир» [16, р. 118]. Сам Д. Уснер в рамках исследования проблемы, конечно, затрагивал годы президентства Дж. Адамса, но при этом больше внимания уделял вопросу формирования американо-индейских отношений, взглядам Дж. Адамса на индейский вопрос [24].

Таким образом, если несколько абстрагироваться от философских воззрений второго президента США на проблему взаимоотношений белых с коренными американцами и, соот- ветственно, идеологической составляющей его поступков, то остаются открытыми два основных вопроса: что в действительности представлял из себя политический курс администрации Дж. Адамса в отношении индейцев и как соотнести утверждение Ф.П. Пручи о том, что индейский вопрос мало интересовал второго президента страны, с конкретными действиями президентской администрации.

Для лучшего понимания проводимой Дж. Адамсом политики надо обозначить сложившуюся к его президентству ситуацию в индейском вопросе.

На территории Соединенных Штатов, оговоренной Парижским мирным договором 1783 г., проживало несколько групп индейских племен. Некоторые из них, так называемые «нефронтирные» племена, в результате долгих лет колонизации уже утратили свои традиционные земли и опасности для США не представляли. Это, например, алгонкиноязычные абенаки северной части Новой Англии, остатки некогда могущественной конфедерации поухатанов в Виргинии, сиуязычные катоба в Северной и Южной Каролине и др. Дела с «нефронтирными» индейцами вели штаты, на территории которых данные племена проживали.

Другое дело - индейцы фронтира, те племена, с которыми у Соединенных Штатов периодически возникали проблемы. Здесь выделяются три основные группы: ирокезы штата Нью-Йорк, индейцы Северо-Западной территории и пять цивилизованных племен юга США.

Из всех этих народов к началу президентства Дж. Адамса ирокезы были самыми спокойными, период их жесткого сопротивления колонизации закончился. Однако не все ирокезы безоговорочно поддерживали американцев, например, могавки Джозефа Бранта, верные союзники англичан, после Войны американских колоний за независимость отказались подписывать договоры с США и ушли в Канаду.

Индейцы Северо-Запада - это преимущественно алгонкиноязычные народы, жившие в 


\section{ВСЕОБЩАЯ ИСТОРИЯ}

районе Великих Озер и в долинах рек Огайо и Уобаш: майами, оджибва (чиппева), отава, потаватоми, сауки и фоксы, кикапу, меномини, иллинойс и др. На востоке долины реки Огайо проживали шауни и мигрировавшие сюда после договора англичан с ирокезами у форта Стенвикс в 1768 г. делавары [11, p. 55]. Кроме того, на Северо-Западе США жили ирокезоязычные гуроны (вайандоты) и минго.

Трудности с этими племенами возникли практически сразу после подписания Парижского мирного договора 1783 года. Во-первых, во время войны они были союзниками англичан и таковыми по сути оставались; во-вторых, согласно положениям второй статьи договора, все земли, на которых проживали эти народы, переходили в собственность США [12, p. 81-82]. Мнение индейцев по этому вопросу никого особо не интересовало ${ }^{1}$.

Подобного рода обстоятельства вызвали недовольство коренных американцев и привели к формированию Западной конфедерации племен, к которой, кроме проживавших на Северо-Западе народов, присоединились еще южане: верхние крики и нижние чероки (чикамога). Главная цель конфедерации индейцев заключалась в сохранении своих земель от посягательств белых колонистов.

Война с Западной индейской конфедерацией, известная также как Война Маленькой Черепахи, длилась десять лет с 1785 по 1795 год. После разгрома индейцев армией генерала Энтони Уэйна в Битве при Фоллен Тимберс 20 августа 1794 г. организованное сопротивление племен прекратилось. Эта тема неплохо раскрыта в историографии, поэтому нет смысла на ней останавливаться подробно [3, p. 57-87; 14; 17; 20]. Достаточно лишь сказать, что после поражения с индейцами был подписан Гринвилльский договор, по которому они теряли земли долины реки Огайо [23]. Естественно не все группы индейцев признавали этот договор. Недовольных было много, и мир по большому счету был непрочный.

Цивилизованные племена юга США ирокезоязычные чероки и четыре мускогоязычных: крики, семинолы, чокто и чикасо были хорошо развиты экономически, вели свое хозяйство не хуже, а подчас и лучше своих белых соседей и представляли серьезную политическую силу на юге страны. Единства в отношении к американцам у них не было. Некоторые группы были дружественными, например, часть чокто и чикасо служили скаутами у генерала Э. Уэйна. Некоторые были настроены враждебно. У криков сложились тесные торговые отношения с испанцами и англичанами, что задавало определенный тон в диалоге с американскими властями. Особенно хорошо это проявилось при попытке американцев заключить договор с криками в 1790 г., тогда пришлось согласиться практически со всеми требованиями аборигенов [2, с. 229].

Таким образом, одна из ключевых проблем индейского вопроса, доставшаяся Дж. Адамсу после Дж. Вашингтона, - это слабый мир с племенами Северо-Запада и потенциальная угроза, исходившая с юга от политически сильных цивилизованных племен. Совершенно очевидно, что в таких условиях Дж. Адамс должен был действовать крайне осторожно, тем более что и внешнеполитическая ситуация в 1797 г. была также непростой: морской конфликт США с Францией вполне мог перейти в полномасштабную войну. Это обстоятельство делало мир с коренными американцами приоритетным направлением индейской политики второго президента.

Чести ради надо отметить, что кроме проблем в индейском вопросе Дж. Вашингтон оставил Дж. Адамсу и разработанный механизм ведения дел с индейцами. В организационном плане все эти дела были в ведении военного департамента. Юридические основы индейской политики были закреплены законом 1796 г. о торговле и взаимоотношениях с индейцами, который по сути воплощал в себе главные достижения администрации первого президента в обеспечении мирного сосуществования белых с коренными американцами. Закон 1796 г. представлял собой свод правил относительно того, как надо и как не надо вести себя на границе, как строить торговые отношения с индейцами, как наказывать нарушителей и т. д. Статья 22 оговаривала срок действия закона - два полных года и затем до конца сессии Конгресса, что фактически затрагивало первые два года президентства Дж. Адамса [8, p. 474].

Как и следовало ожидать, в начале своего президентства каких-то радикальных шагов в решении индейского вопроса Дж. Адамс 
не предпринимал. В своем первом ежегодном послании Конгрессу от 22 ноября 1797 г. президент уделил индейской тематике совсем немного внимания, гораздо больше - отношениям с Францией. Тем не менее в этом выступлении прозвучала, хоть и опосредованно, очень важная мысль - необходимость сохранения мира с коренными американцами. Дж. Адамс сообщал, что на индейской территории действовали иностранные агенты, подстрекавшие аборигенов к войне против США [13, p. 251-252]. Президент не отмечал страну, от лица которой действовали эти агенты, хотя очевидно, что он имел в виду, прежде всего, Великобританию. Дело в том, что изза статьи 2 Договора Джея 1794 г. на северозападе Огайо создавалась несколько странная ситуация: с одной стороны, англичане убирали с американской территории все военные посты, которые остались еще со времен Войны за независимость; с другой, английские торговцы получали право вести свой бизнес на территории Соединенных Штатов в неограниченном масштабе [21, p. 117]. Несомненно, такое положение дел создавало угрозу национальной безопасности США, поскольку через английских торговцев шло и негативное влияние на местных индейцев.

Что касается испанцев, то с их стороны никакого подстрекательства коренных американцев против США не ожидалось. Об этом Дж. Адамс сообщал Конгрессу еще в июне 1797 г. [15, p. 246]. Однако в первом ежегодном послании президент выразил озабоченность по поводу того, что испанцы не исполняли должным образом свои обязательства по выводу войск с территории Соединенных Штатов, а это, как отмечалось, могло способствовать проявлению враждебности со стороны индейцев [13, p. 251].

Учитывая сложившиеся обстоятельства, Дж. Адамс предлагал Конгрессу рассмотреть вопрос о принятии закона, пресекавшего пагубные действия иностранных агентов: «Хотя были приняты меры по противодействию этим нарушениям наших прав, предотвращению враждебности индейцев и сохранению их полной привязанности к Соединенным Штатам, моим долгом является заметить, что для придания лучшего эффекта этим мерам и устранения последствий таких практик, возможно, необхо- дим закон, предусматривающий адекватное наказание за подобные нарушения» [13, p. 252].

Второй год президентства Дж. Адамса также прошел без индейских реформ, но при этом не было отмечено и конфликтов. Осторожная тактика, судя по всему, приносила свои хоть и скромные, но очень нужные плоды. Во втором ежегодном послании Конгрессу президент опять уделил основное внимание внешнеполитическим опасностям страны. Индейцы были упомянуты лишь несколькими фразами в контексте демаркации границ с Испанией. Сложности возникли из-за того, что аборигены препятствовали проведению границы [19, p. 263-264]. Никакие конкретные племена Дж. Адамс не называл, хотя очевидно, что имелись в виду крики, чья территория по положениям статьи 2 Договора Пинкни 1795 г. была разделена между США и Испанией по 31 параллели [22, p. 138-140].

В начале марта 1799 г. заканчивался срок действия закона 1796 г. о торговле и взаимоотношениях с индейцами. Уже 3 марта 1799 г. был принят соответствующий новый закон [9]. Проводя сравнительный анализ данного законодательного акта с его предшественником, можно увидеть, что положения закона 1799 г. в большинстве своих пунктов практически полностью идентичны положениям закона 1796 года. Различия носят больше технический и организационный характер: в статье 1 обозначена актуальная к тому моменту граница с индейцами; статья 16 уточняет правила конвоирования нарушителей и т. д. Основные же правила поведения на границе остались неизменными. Как заметил Ф.П. Пруча, совершенно очевидно, что закон 1799 г. прошел через обе палаты Конгресса без поправок и без долгих обсуждений, не внеся при этом ничего принципиально нового в организацию взаимоотношений с аборигенами [16, p. 93]. Такое сходство может свидетельствовать, с одной стороны, о том, что Дж. Адамсу ввиду сложной международной обстановки было некогда заниматься вопросами индейцев; с другой, что более вероятно, действенность закона 1796 г. была подтверждена относительным затишьем в индейском вопросе, а значит, закон мог рассматриваться администрацией второго президента как удачный и не требующий радикальных перемен. 
В 1800 г. правительство страны приняло несколько актов, в той или иной степени относившихся к индейской тематике. По своей сути это были лишь небольшие уточнения к уже проводившейся политике. Первым актом такого рода стал акт о поддержании мира с индейскими племенами от 17 января 1800 года. Этот документ можно рассматривать как несколько запоздалую реакцию конгрессменов на предложение Дж. Адамса, высказанное в его первом ежегодном послании Конгрессу в 1797 г. по поводу ужесточения мер наказания лицам, подстрекавшим коренных американцев к конфликту с США. В части 1 данного акта для таких лиц предусматривалось наказание штрафом в размере двух тысяч долларов и заключением в тюрьму на срок до двух лет. Тем же, кто просто доставлял или передавал индейцам призыв к конфликту с Соединенными Штатами, согласно частям 2 и 3 , предусматривался штраф в размере одной тысячи долларов и срок тюремного заключения до двенадцати месяцев. Акт о поддержании мира с индейцами 1800 г., согласно его пятой статье, был в силе до 3 марта 1802 г. [5].

22 апреля 1800 г. была принята поправка к Закону 1799 г. о торговле и взаимоотношениях с индейцами, оговаривавшая правила задержания и конвоирования нарушителей [7]. В этот же день конгрессмен от Теннесси Уильям Клайборн отчитался перед Палатой представителей о деятельности комитета по изучению целесообразности продления принятых еще при Дж. Вашингтоне актов об учреждении торговых фортов. Таких актов было два. Первый экспериментальный от 3 марта 1795 г. предполагал выделение суммы в 50 тысяч долларов для организации государственной торговли с индейцами [6]. Согласно ему, в том же 1795 г. было установлено две фактории: одна для криков - Колерейн на реке СентМэрис в Джорджии; другая для чероки и чикасо - у блокпоста Теллико в восточном Теннесси [18]. Поскольку эксперимент оказался удачным, 18 апреля 1796 г. был принят второй акт, оговаривавший правила учреждения и функционирования системы факторий [4]. Однако с того момента новых государственных факторий не появилось, если конечно не считать перенос торгового поста Колерейн севернее к Форту Уилкинсон в 1797 году. Но несмотря на это обстоятельство, У. Клайборн все равно рекомендовал Конгрессу продлить действие так называемого закона о факториях [26].

1800 г. показал, что тактика затишья имела побочные эффекты, поскольку создавала опасность замораживания некоторых прогрессивных достижений предыдущей администрации. Одно из главных в политике первого президента средств взаимодействия с индейцами - система факторий - начало давать сбои. Рекомендация продлить основанную при Дж. Вашингтоне модель государственной торговли с индейцами не была принята безоговорочно, как это было, например, с законом о торговле и взаимоотношениях с индейцами 1799 года. Пришлось прилагать некие усилия, чтобы эту идею протолкнуть.

5 февраля 1801 г. У. Клайборн повторно выступил перед Палатой представителей, отчитался о финансовой стороне работы двух учрежденных факторий и обратил внимание конгрессменов на то обстоятельство, что действие закона о факториях 1796 г. уже закончилось, а закон, продлевавший систему, так все еще и не был принят. В этой связи У. Клайборн призывал Конгресс принять решение о продлении закона о факториях [27].

Очевидно, что вопрос был не в экономической выгоде, а в стратегической значимости факторий. Контролируемые государством торговые посты, по замыслу Дж. Вашингтона, должны были препятствовать распространению нелегальной торговли, предотвращать случаи мошенничества в торговых сделках, пресекать враждебные действия иностранных агентов-подстрекателей, то есть бороться с теми факторами, которые вели к обострению отношений с индейцами. Кроме того, через фактории должно было идти просвещение коренных американцев, развитие у них навыков цивилизованного образа жизни [1, с. 50-51]. Однако теперь вся система факторий была под угрозой - старания У. Клайборна не возымели успеха, и Дж. Адамс не стал переубеждать Конгресс. Это обстоятельство несколько не вписывается в прослеживаемую в первые три года президентства Дж. Адамса политическую линию - следовать курсу Дж. Вашингтона и сохранять мир с индейца- 
ми. Поступок Дж. Адамса можно объяснить двумя обстоятельствами. Во-первых, уместно предположить, что президент особо не верил в эффективность системы факторий, всетаки за четыре года, с 1797 по 1801 г., новых торговых постов основано не было. И хотя большинство племен фронтира не имело доступа к факториям, мир с индейцами поддерживать все равно получалось. Во-вторых, Дж. Адамс не хотел обострять отношения с Конгрессом, тем более что у него были разногласия со своими однопартийцами в вопросах внешней политики.

Как бы то ни было, система факторий в результате так и не получила при втором президенте законодательного продолжения. Необходимый закон о ее продлении был принят только при Т. Джефферсоне 30 апреля 1802 г. [10].

Подводя итог президентству Дж. Адамса, следует сказать, что за годы его нахождения у власти каких-то выдающихся событий или кардинальных реформ в индейском вопросе не произошло. Законодательные и подзаконные акты, принятые при Дж. Адамсе, были в русле политики Дж. Вашингтона. При этом их нельзя считать индейскими в прямом смысле этого слова, поскольку они касались больше полномочий президента и правил поведения граждан на границе. Права коренных американцев особо не оговаривались, что собственно и понятно, поскольку индейцы тогда еще не были гражданами США. Система факторий развития не получила. Более того, к концу президентского срока Дж. Адамса даже возникла угроза консервирования проекта.

Можно лишь отчасти согласиться с Ф.П. Пручей в том, что индейский вопрос мало интересовал Дж. Адамса. Действительно, в пользу этого тезиса говорит бедность всего срока правления второго президента на правительственные постановления, касавшиеся аборигенов. Однако тезис Ф.П. Пручи справедлив только вне контекста происходящих в стране событий. Политический курс, который выстраивал второй президент в отношении индейцев, складывался в условиях сложной внутренней и внешнеполитической обстановки США. Одной из ключевых задач Дж. Адамса в сложившейся ситуации было уберечь страну от вступления в полномасштабную войну с Францией. При этом ему приходилось выдерживать внутрипартийное давление со стороны выступавшего за войну лидера федералистов Александра Гамильтона, а также критику демократических республиканцев. Совершенно очевидно, что в таких условиях проблемы с индейцами были не нужны. Как следствие, вполне логично, что свой политический курс в отношении коренных американцев Дж. Адамс формировал в канве политического курса Дж. Вашингтона, стараясь максимально снизить как недовольство индейцев, так и недовольство политиков. Собственно с решением первой задачи Дж. Адамс как раз хорошо справился, за четыре года его президентства у американцев не было ни одного серьезного конфликта с индейцами. Так что Дж. Адамс впоследствии гордился, что сумел сохранить мир с коренными американцами вполне оправданно. В связи с этим надо заметить, что политический курс администрации Дж. Адамса в отношении индейцев хоть и не стал ярким эпизодом американской истории, но был одним из наименее болезненных как для белого населения, так и для коренных американцев.

\section{ПРИМЕЧАНИЯ}

${ }^{1}$ С правами коренных американцев на землю по большому счету ни европейские державы, ни американцы не считались. Территории передавались в рамках международных соглашений вместе с жителями. Договоры с индейцами, где речь шла о земельных уступках, лишь по форме напоминали международные, но в действительности таковыми не были. Земельные уступки в этих договорах по сути являлись актом отчуждения частной собственности в рамках государства, но никак не приобретением новой государственной территории.

\section{СПИСОК ЛИТЕРАТУРЫ}

1. Нелин, Т. В. Американская политика просвещения индейских племен (конец XVIII - начало XIX) / Т. В. Нелин // Вестник Волгоградского государственного университета. Серия 4, История. Регионоведение. Международные отношения. 2014. - № 1 (25). - C. 49-56. - DOI: http://dx.doi.org/ 10.15688/jvolsu4.2014.1.5. 
2. Нелин, Т. В. Непростой путь к миру: история первого договора администрации США с племенем криков / Т. В. Нелин // Americana : сб. науч. тр., посвящ. 60-летию д-ра ист. наук, проф. А.И. Кубышкина. - Волгоград: Изд-во ВолГУ, 2010. Вып. 11.-С. 220-231.

3. Allen, R. S. His Majesty's Indian Allies: British Indian Policy in The Defence of Canada, 1774 1815 / R. S. Allen. - Toronto ; Oxford : Dundurn Press, 1993. $-294 \mathrm{p}$.

4. An act for establishing trading houses with the Indian tribes. Apr. 18. 1796// United States Statutes at Large, 1789-1875. In 18 vols. / ed. by R. Peters. Boston : Charles C. Little and James Brown, 1845. Vol. 1. - P. 452-453.

5. An act for the preservation of peace with the Indian tribes. Jan. 17. 1800 // United States Statutes at Large. - Boston, 1845. - Vol. 2. - P. 6-7.

6. An act making provision for the purposes of trade with the Indians. March 3. 1795 // United States Statutes at Large. - Boston, 1845. - Vol. 1.P. 443.

7. An Act supplementary to the Act to regulate trade and intercourse with the Indian Tribes, and to preserve peace on the Frontiers. Apr. 22. $1800 / /$ United States Statutes at Large. - Boston, 1845. - Vol. 2. P. 39-40.

8. An act to regulate trade and intercourse with the Indian tribes, and to preserve peace on the frontiers. May 19. 1796 // United States Statutes at Large. - Boston, 1845. - Vol. 1. - P. 469-474.

9. An act to regulate trade and intercourse with the Indian tribes, and to preserve peace on the frontiers. March 3. 1799 // United States Statutes at Large. - Boston, 1845. - Vol. 1. - P. 743-749.

10. An Act to revive and continue in force, an act intituled "An act for establishing trading houses with the Indian tribes." Apr. 30. 1802 // United States Statutes at Large. - Boston, 1845. - Vol. 2. - P. 173.

11. Carter, H. L. The Life and Times of Little Turtle: First Sagamore of the Wabash / H. L. Carter. - Urbana (Ill.) ; Chicago : University of Illinois Press, 1985. $275 \mathrm{p}$.

12. Definitive treaty of peace between the United States of America and his Britannic Majesty. Sept. 3. 1783 // United States Statutes at Large. - Boston : Little, Brown and Company, 1867. - Vol. 8. - P. 80-83.

13. First Annual Address of John Adams. Nov. 22. 1797 // A Compilation of the Messages and Papers of the Presidents, 1789-1897. In 11 vols / ed. by J. D. Richardson. - Washington, D. C. : Government Printing Office, 1896. - Vol. 1 : 1789-1817.-P. 250-254.

14. Gaff, A. D. Bayonets in the Wilderness: Anthony Wayne's Legion in the Old Northwest / A. D. Gaff. - Norman (Okl.) : University of Oklahoma Press, 2004. -416 p.
15. John Adams to the Senate and House of Representatives. June 12. 1797 // A Compilation of the Messages and Papers of the Presidents. - Washington, D. C., 1896. - Vol. 1. - P. 246-247.

16. Prucha, F. P. The Great Father. The United States Government and the American Indians. Volumes I and II. Unabridged / F. P. Prucha. - Lincoln (Neb.) ; L. : University of Nebraska Press, 1995. - 1302 p.

17. Prucha, F.P. TheSword of the Republic: The United States Army on the Frontier, 1783-1846 / F. P. Prucha. Lincoln (Neb.) : University ofNebraska Press, 1986.-475 p.

18. Report of the Secretary of War of the measures taken for opening a trade with the Indians. Dec. 12. 1795 // American State Papers. Documents, legislative and executive, of the Congress of the United States: Class 2: Indian Affairs. In 2 vols. / ed. by W. Lowrie and M. St. Clair Clarke. - Washington, D. C. : Gales and Seaton, 1832. - Vol. 1. - P. 583-584.

19. Second Annual Address of John Adams. Dec. 8. 1798// ACompilation of the Messages and Papers of the Presidents. - Washington, D. C., 1896. - Vol. 1.P. 261-265.

20. Sword, W. President Washington's Indian War: The Struggle for the Old Northwest, 1790-1795 / W. Sword. - Norman (Okl.) ; L. : University of Oklahoma Press, 1985. -400 p.

21. Treaty of Amity, Commerce, and Navigation, Between His Britannic Majesty and the United States of America, by their President, with the Advice and Consent of their Senate. Nov. 19. 1794 // United States Statutes at Large. - Boston, 1867. - Vol. 8. - P. 116-129.

22. Treaty of Friendship, Limits, and Navigation, Between the United States of America and the King of Spain. Oct. 27. 1795 // United States Statutes at Large. Boston, 1867. - Vol. 8. - P. 138-153.

23. Treaty with the Wyandot, etc. Aug. 3. 1795 // Indian Affairs: Laws and Treaties. In 7 vols. / comp. and ed. by C. J. Kappler. - Washington, D. C. : Government Printing Office, 1904. - Vol. 2 : Treaties. P. 39-45.

24. Usner, D. H. "A Savage Feast They Made Of It": John Adams and the Paradoxical Origins of Federal Indian Policy / D. H. Usner // Journal of the Early Republic. - 2013. -Vol. 33. - №4(Winter). - P. 607-641.

25. Wallace, A. F. C. Jefferson and the Indians: The Tragic Fate of the First Americans / A. F. C. Wallace. Cambridge (Mass.) ; L. : Harvard University Press, 1999. -394 p.

26. William C. C. Claiborne to the House of Representatives. Apr. 22. 1800 // American State Papers. Indian Affairs. - Washington, D. C., 1832.Vol. 1. - P. 643.

27. William C. C. Claiborne to the House of Representatives. Feb. 5. 1801 // American State Papers. Indian Affairs. - Washington, D. C., 1832. - Vol. 1.P. 646. 


\section{ВСЕОБЩАЯ ИСТОРИЯ}

\section{REFERENCES}

1. Nelin T.V. Amerikanskaya politika prosveshcheniya indeyskikh plemen (konets XVIII nachalo XIX) [American Education Policy Towards Indian Tribes (the End of the 18th - Beginning of the 19th Century)]. Vestnik Volgogradskogo gosudarstvennogo universiteta. Seriya 4, Istoriya. Regionovedenie. Mezhdunarodnye otnosheniya [Science Journal of Volgograd State University. History. Area Studies. International Relations], 2014, no. 1 (25), pp. 49-56. DOI: http://dx.doi.org/10.15688/ jvolsu4.2014.1.5.

2. Nelin T.V. Neprostoy put $\mathrm{k}$ miru: istoriya pervogo dogovora administratsii SShA s plemenem krikov [Uneasy Way to Peace: the History of the First Treaty Between the USA and the Creek Nation]. Americana: sb. nauch. tr., posvyashch. 60-letiyu d-ra ist. nauk, prof. A.I. Kubyshkina [Americana: Collected Scientific Articles Devoted to the $60^{\text {th }}$ anniversary of Doctor of Historical Sciences, Professoor A.I. Kubyshkin]. Volgograd, Izd-vo VolGU, 2010, iss. 11,pp. 220-231.

3. Allen R.S. His Majesty's Indian Allies: British Indian Policy in The Defence of Canada, 1774-1815. Toronto, Oxford, Dundurn Press, 1993. 294 p.

4. An Act for Establishing Trading Houses With the Indian Tribes. April 18, 1796. Peters R., ed. United States Statutes at Large, 1789-1875. Boston, Charles C. Little and James Brown, 1845, vol. 1, pp. 452-453.

5. An Act for the Preservation of Peace With the Indian Tribes. January 17, 1800. Peters R., ed. United States Statutes at Large. Boston, 1845, vol. 2, pp. 6-7.

6. An Act Making Provision for the Purposes of Trade With the Indians. March 3, 1795. Peters R., ed. United States Statutes at Large. Boston, 1845, vol. 1, p. 443.

7. An Act Supplementary to the Act to Regulate Trade and Intercourse With the Indian Tribes, and to Preserve Peace on the Frontiers. April 22, 1800. Peters R., ed. United States Statutes at Large. Boston, 1845, vol. 2, pp. 39-40.

8. An Act to Regulate Trade and Intercourse With the Indian Tribes, and to Preserve Peace on the Frontiers. May 19, 1796. Peters R., ed. United States Statutes at Large. Boston, 1845, vol. 1, pp. 469-474.

9. An Act to Regulate Trade and Intercourse With the Indian Tribes, and to Preserve Peace on the Frontiers. March 3, 1799. Peters R., ed. United States Statutes at Large. Boston, 1845, vol. 1, pp. 743-749.

10. An Act to Revive and Continue in Force, an Act Intituled "An Act for Establishing Trading Houses With the Indian Tribes". April 30, 1802. Peters R., ed.
United States Statutes at Large. Boston, 1845, vol. 2, p. 173.

11. Carter H.L. The Life and Times of Little Turtle: First Sagamore of the Wabash. Urbana (Ill.), Chicago, University of Illinois Press, 1985. 275 p.

12. Definitive Treaty of Peace Between the United States of America and his Britannic Majesty. September 3, 1783. Peters R., ed. United States Statutes at Large. Boston, Little, Brown and Company, 1867, vol. 8, pp. 80-83.

13. First Annual Address of John Adams. November 22, 1797. Richardson J.D., ed. A Compilation of the Messages and Papers of the Presidents, 1789-1897. In 11 vols. Washington, D.C., Government Printing Office, 1896, vol. 1: 1789-1817, pp. 250-254.

14. Gaff A.D. Bayonets in the Wilderness: Anthony Wayne's Legion in the Old Northwest. Norman (Okl.), University of Oklahoma Press, 2004. $416 \mathrm{p}$.

15. John Adams to the Senate and House of Representatives. June 12, 1797. Richardson J. D., ed. A Compilation of the Messages and Papers of the Presidents. Washington, D. C., 1896, vol. 1, pp. 246-247.

16. Prucha F.P. The Great Father. The United States Government and the American Indians. Volumes I and II. Unabridged. Lincoln (Neb.), L., University of Nebraska Press, 1995. 1302 p.

17. Prucha F.P. The Sword of the Republic: The United States Army on the Frontier, 1783-1846. Lincoln (Neb.), University of Nebraska Press, 1986. $475 \mathrm{p}$.

18. Report of the Secretary of War of the Measures Taken for Opening a Trade With the Indians. December 12, 1795. Lowrie W., St. Clair Clarke M., eds. American State Papers. Documents, legislative and executive, of the Congress of the United States: Class 2: Indian Affairs. Washington, D. C., Gales and Seaton, 1832, vol. 1, pp. 583-584.

19. Second Annual Address of John Adams. December 8, 1798. Richardson J.D., ed. A Compilation of the Messages and Papers of the Presidents, 17891897. Washington, D. C., Government Printing Office, 1896, vol. 1, pp. 261-265.

20. Sword W. President Washington's Indian War: The Struggle for the Old Northwest, 1790-1795. Norman (Okl.), L., University of Oklahoma Press, 1985. $400 \mathrm{p}$.

21. Treaty of Amity, Commerce, and Navigation, Between His Britannic Majesty and the United States of America, by their President, with the Advice and Consent of their Senate. November 19, 1794. Peters R., ed. United States Statutes at Large. Boston, 1867, vol. 8, pp. 116-129.

22. Treaty of Friendship, Limits, and Navigation, Between the United States of America 
and the King of Spain. October 27, 1795. Peters R., ed. United States Statutes at Large. Boston, 1867 , vol. 8, pp. 138-153.

23. Treaty With the Wyandot, etc. August 3, 1795. Kappler C. J., ed. Indian Affairs: Laws and Treaties, Washington, D. C., Government Printing Office, 1904, vol. 2: Treaties, pp. 39-45.

24. Usner D. H. "A Savage Feast They Made Of It": John Adams and the Paradoxical Origins of Federal Indian Policy. Journal of the Early Republic, 2013, vol. 33, no. 4 (Winter), pp. 607-641.
25. Wallace A.F.C. Jefferson and the Indians: The Tragic Fate of the First Americans. Cambridge (Mass.), L., Harvard University Press, 1999. 394 p.

26. William C.C. Claiborne to the House of Representatives. April 22, 1800. Lowrie W., St. Clair Clarke M., eds. American State Papers. Indian Affairs. Washington, D.C., 1832, vol. 1, p. 643.

27. William C.C. Claiborne to the House of Representatives. February 5, 1801. Lowrie W., St. Clair Clarke M., eds. American State Papers. Indian Affairs. Washington, D. C., 1832, vol. 1, p. 646. 